\title{
DEBATE
}

\section{Incomplete overlapping of biological, clinical, and environmental information in molecular epidemiological studies: a variety of causes and a cascade of consequences}

\author{
M Porta, N Malats, J Vioque, A Carrato, M Soler, L Ruiz, V Barberà, D Ayude, F X Real
}

$\mathrm{R}$ ecent scientific, political, industrial, and public relations efforts to publicise the first interpretations of the human genome sequence raised unprecedented social expectations towards the health sciences ${ }^{1-6}$; yet, prudence seems warranted when assessing the relevance of emerging genomic knowledge to lessen the burden of illness in human populations. ${ }^{7-9}$ Among the formidable tasks that lie ahead, it will be important to achieve a proper understanding of how genes and the environment interact to cause human disease. ${ }^{10-14}$ This aim will partly depend on how molecular epidemiological studies are conducted. Long viewed as a promising approach, ${ }^{15}$ molecular epidemiology is no longer in its infancy ${ }^{16-25}$ Figure 1 shows that the number of studies ascribed to molecular epidemiology increased dramatically during the past decade. Yet, as shown in table 1 and figure 2, "molecular epidemiological" studies are just a fraction of studies attempting to integrate epidemiological, genetic, and molecular dimensions of disease. Even if nowadays some features of molecular epidemiological studies retain some novelty, other basic challenges have always been undisputed. ${ }^{11}$ Prominently, the need to integrate valid biological, clinical, and epidemiological information from unbiasedly selected populations. Indeed, tumour tissue procurement and, more generally, the availability of biological samples are crucial in molecular epidemiology. However, although completeness of the "biological study base" is frequently hampered by ethical, clinical, and logistic factors, these are rarely analysed in depth. Unaccountably, molecular epidemiological studies often fail to properly assess whether selection biases affect their results. ${ }^{26}$ Exceptions do exist, of course. One is the study by Slattery et al-interestingly, published in Mutation Research Genomics. ${ }^{27}$ The authors were able to collect blocks and extract DNA for 2117 of 2477 people ( $86 \%$ ) for whom they had permission to obtain tumour blocks. They found no differences in age, tumour site, or diet and lifestyle characteristics between subjects with and without DNA extracted. However, they were less likely to be able to extract DNA if the case was diagnosed at a more advanced disease stage or at the earliest stage.

\section{INCOMPLETE OVERLAPPING OF BIOLOGICAL, CLINICAL, AND ENVIRONMENTAL INFORMATION: AN EXAMPLE}

Studies providing opportunities to think about the consequences of an incomplete overlapping of biological, clinical, and environmental information abound. ${ }^{26}{ }^{28} 29$ Of course, they include our own, where we have often tried to control the problem-not always successfully-and to discuss such consequences. ${ }^{26}{ }^{30-35}$ Another recent example is the case-case study by Slebos et al. ${ }^{36}$ It investigated whether in pancreatic cancer alterations in the K-ras and $p 53$ genes may be related

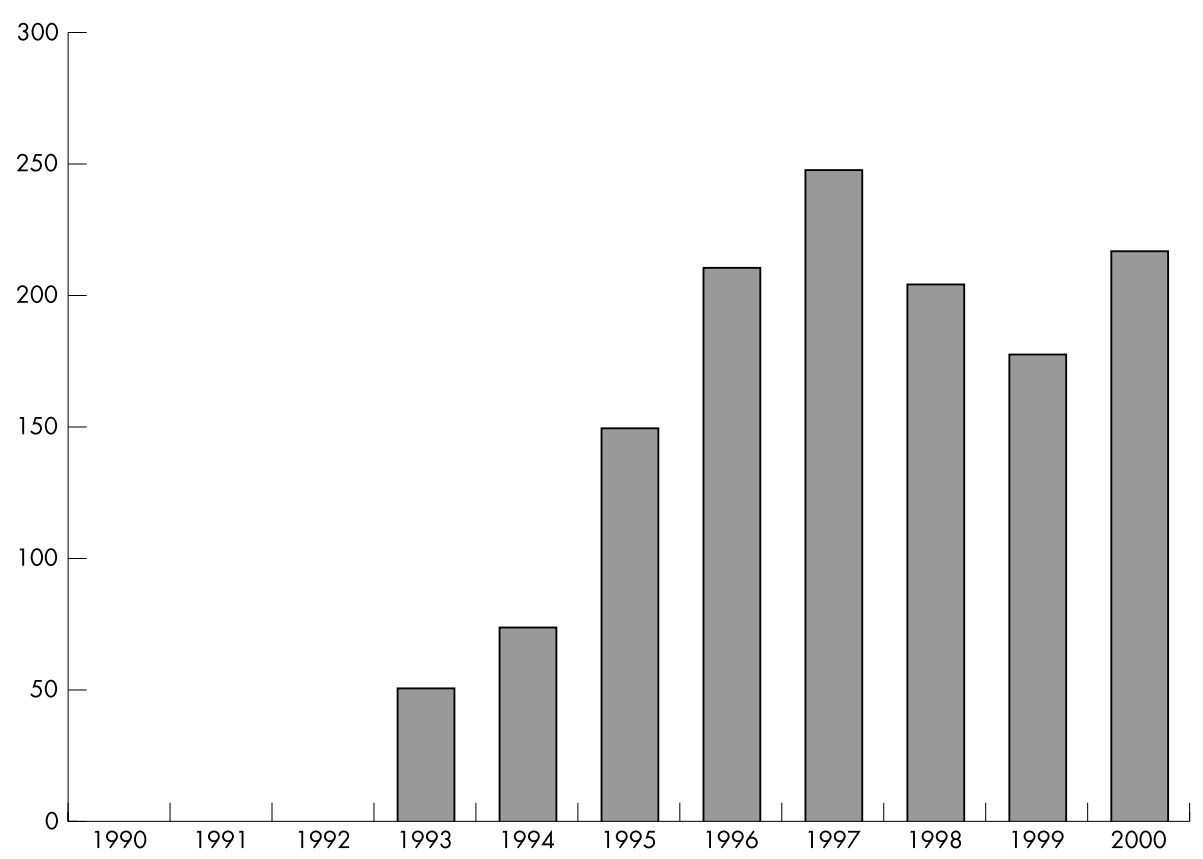

Figure 1 Number of articles from "molecular epidemiological" studies (column $\mathrm{A}$ of the table). 


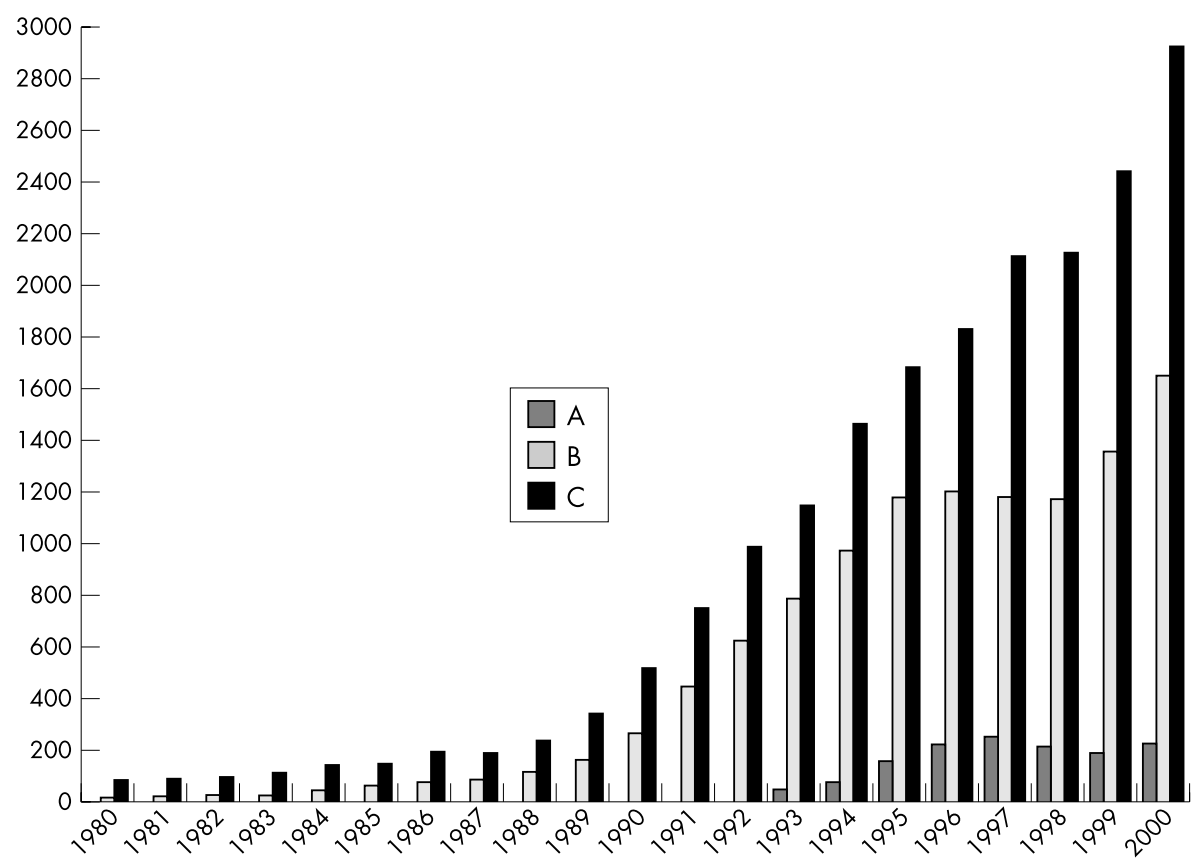

Figure 2 Number of articles with the terms mentioned in columns $A, B$, and $\mathrm{C}$ of the table.

with aspects of the patients' medical history, the histopathology of tumours, and environmental exposures. The study deserves to be commended on a number of strengths, including the use of advanced techniques for the molecular analyses of pure populations of tumour cells, the attempt to account for subjects that could not be included in genetic and organochlorine compounds analyses, and the cautious conceptualisation of the results. Such strengths notwithstanding, the study has potentially important limitations. The causes and consequences of such weaknesses merit analysis for two main reasons: firstly, because some of the study conclusions might be erroneous; and secondly, of even broader interest, because the limitations may illustrate some potential pitfalls of molecular epidemiological research.

This debate concerns many scholars who work on molecular epidemiology, and very directly those who study pancreatic cancer and other cancers whose diagnosis is especially difficult. To broadly contextualise the debate, the following facts are worth noting: over 12 years after their high prevalence at diagnosis was first reported, point mutations in the K-ras gene remain the most consistent genetic alteration in exocrine pancreatic cancer. Even more important, K-ras mutations are one of the most common genetic alterations in human cancers-probably, the most frequent somatic (acquired) oncogene mutation. ${ }^{37}$ It is hence puzzling that so little evidence is available for or against the hypothesis that the occurrence and persistence of K-ras mutations may be related to environmental factors. Let us then synthesise the main limitations of the study by Slebos et al, and analyse their potential effects upon their conclusions.

- Out of some $611,{ }^{38}$ "more than $5500^{\prime,},{ }^{36}$ or $374(321+53)^{36}$ eligible patients, 61 (16\%), 49 (13\%), and $24(6 \%)$ were integrated in the analyses of K-ras, $p 53$ and organochlorine compounds, respectively (percentages are for 374). Because the percentage of patients potentially eligible for inclusion who were finally analysed is low by conventional epidemiological standards, it seems pertinent to ask why. A possible explanation regards the fact that about $55 \%{ }^{38}$ or more ${ }^{36}$ of cases were deceased when contacted. This possibility should make us think about methods we use to identify eligible patients, and about practical ways to shorten the distance between the clinicians who diagnose cases and the epidemiologistsresearchers. It is also possible that the low percentage of cases analysed was partly attributable to the fact that about two thirds of patients without surgical tumour material were excluded. ${ }^{36}$ If so, maybe the authors should have kept in mind the possibility of retrieving cytohistological samples from fine needle aspiration and endoscopic or laparoscopic procedures, which most patients undergo, ${ }^{39}$ and which permit efficient analyses of K-ras and $p 53$. The evolution of diagnostic technologies and clinical algorithms is a permanent challenge to researchers trying to minimise selection biases. It deserves similar attention than laboratory techniques suitable for population studies. ${ }^{20} 26{ }^{33}{ }^{40-42}$ We are aware that the description of the process followed to select cases is at other times much less comprehensive ${ }^{28}{ }^{29}$ than in the article by Slebos et al. ${ }^{36}$ We have also experienced the difficulties that these issues present when due respect is given to ethical and clinical matters. ${ }^{26} 303143$ In the PANKRAS II Study, for example, we analysed K-ras in 121 of 185 potential subjects $(65 \%){ }^{32}$ Both K-ras and organochlorine compounds were initially assessed in $51(27 \%)$ patients ${ }^{33}$; this was largely by design, as it was a pioneer study. We also provided a detailed comparison of the 51 patients included and the 134 patients initially excluded. ${ }^{34}$ Modest steps, admittedly, but in the right direction.

- Slebos et al provided an interesting comparison of some characteristics of patients included (as their tumour blocks were available, $n=61)^{36}$ and of patients included only in the original case-control study based on cases selected from the San Francisco Bay Area $(n=321) .{ }^{38}$ It is unclear, however, how many of the 61 cases originated from the 321 cases, as some of the 61 patients came from 53 additional cases later retrieved from the University of California at San Francisco (UCSF) pathology records. It is also unclear if the latter cases were interviewed in a similar way as the former. ${ }^{36}$ It would also have helped (to assess the validity of results on organochlorine compounds) that the authors had provided data on their respective times of blood sampling (which apparently occurred about three months after diagnosis in the original study). ${ }^{38}$ These issues concern a large number of molecular epidemiological studies that tend to use patients from a variety of clinical settings in order to palliate the low number of cases with biological samples available to researchers. 


\begin{tabular}{|c|c|c|c|}
\hline Year & $\begin{array}{l}\text { "Epidemiology, } \\
\text { molecular" A }\end{array}$ & $\begin{array}{l}\text { "Epidemiology" and } \\
\text { "molecular" B }\end{array}$ & $\begin{array}{l}\text { "Epidemiology" and } \\
\text { "gene" C }\end{array}$ \\
\hline 2000 & $\begin{array}{l}216 \\
178\end{array}$ & 1638 & 2912 \\
\hline 1999 & 178 & 1343 & 2419 \\
\hline 1998 & 204 & 1165 & 2108 \\
\hline 1997 & 247 & 1175 & 2093 \\
\hline 1996 & 210 & 1194 & 1817 \\
\hline 1995 & 147 & 1173 & 1675 \\
\hline 1994 & 73 & 963 & 1439 \\
\hline 1993 & 49 & 778 & 1125 \\
\hline 1992 & 0 & 620 & 977 \\
\hline 1991 & 0 & 437 & 739 \\
\hline 1990 & 0 & 255 & 508 \\
\hline 1989 & 0 & 158 & 336 \\
\hline 1988 & 0 & 120 & 229 \\
\hline 1987 & 0 & 85 & 184 \\
\hline 1986 & 0 & 79 & 190 \\
\hline 1985 & 0 & 64 & 144 \\
\hline 1984 & 0 & 51 & 140 \\
\hline 1983 & 0 & 33 & 109 \\
\hline 1982 & 0 & 26 & 91 \\
\hline 1981 & 0 & 21 & 88 \\
\hline 1980 & 0 & 13 & 77 \\
\hline 1979 & 0 & 13 & 70 \\
\hline 1978 & 0 & 10 & 71 \\
\hline 1977 & 0 & 14 & 67 \\
\hline 1976 & 0 & 16 & 51 \\
\hline 1975 & 0 & 9 & 79 \\
\hline 1974 & 0 & 6 & 53 \\
\hline 1973 & 0 & 6 & 41 \\
\hline 1972 & 0 & 6 & 25 \\
\hline 1971 & 0 & 3 & 22 \\
\hline 1970 & 0 & 8 & 24 \\
\hline 1969 & 0 & 2 & 16 \\
\hline 1968 & 0 & 2 & 15 \\
\hline 1967 & 0 & 4 & 13 \\
\hline 1966 & 0 & 0 & 1 \\
\hline 1965 & 0 & 1 & 3 \\
\hline 1964 & 0 & 0 & 0 \\
\hline 1963 & 0 & 0 & 0 \\
\hline 1962 & 0 & 0 & 0 \\
\hline 1961 & 0 & 0 & 0 \\
\hline 1960 & 0 & 0 & 0 \\
\hline
\end{tabular}

Column B also includes the term for column $A$, and column $C$ also includes the terms for columns $A$ and $B$. Search performed on 20 September 2001.

- It would have been useful for Slebos et al to compare several other characteristics of cases included and excluded; prominently, tumour stage at diagnosis (or at the time of blood extraction, if available). Staging information is essential in any molecular epidemiological study of clinically aggressive diseases as pancreatic cancer. It is even more important when studying organochlorine compounds because lipid mobilisation (which might spuriously increase serum organochlorine concentrations) is more likely with increasing cancer dissemination. ${ }^{44}$ We are not aware of scientific evidence supporting the claim ${ }^{38}$ that lipid levels may "stabilise" after a diagnosis of pancreatic cancer. We suggest it might also be of interest to have data on treatments given before blood sampling (because some might change serum organochlorine concentrations), changes in BMI (or weight loss), symptoms before blood collection, and lipid concentrations for the subsets of patients included and excluded from the original ${ }^{38}$ and the new study. ${ }^{36}$

- The comparison of characteristics could have been extended to the 49 and the 24 cases available, respectively, for p53 and organochlorine compounds analyses, as main conclusions of the study are based on the latter two groups. Briefly, the point is: while the attempts to describe subjects that could not be included in genetic and environmental analyses made by Slebos et al, ${ }^{36}$ Slattery et $a l^{27}$ and ourselves are praiseworthy, the descriptions are often incomplete. The fact that most other studies do worse is of little comfort. ${ }^{2630}$

Can the previous problems on selection and information bias be of any consequence? The next set of issues suggests that they can.

In pancreatic cancer, tumour stage at diagnosis has consistently been found to be unrelated to K-ras mutation status by the larger studies. ${ }^{30-47}$ It is hence worth thinking why in the study by Slebos et al the $15 \mathrm{~K}$-ras wild-type patients had more localised tumours than the 46 patients with K-ras mutations ${ }^{36}$ : the former were over three times more likely to have stage I tumours than the latter $(\mathrm{OR}=$ 3.86, 95\% CI: 1.02 to 14.62 ). We see no clear explanation for this association. Perhaps a selection bias occurred, probably because of the small number of subjects. As said, the issue is also interesting because it may illustrate the cascade of consequences that selection bias may have for causal estimation. In this instance, the consequences may have been threefold.

- The authors found ${ }^{36}$ that diabetes was more common among patients with wild type K-ras (six cases) than among patients with K-ras mutations (two cases). The finding was never reported before. But pancreatic cancer 
may be diagnosed at earlier stages in people with diabetes, ${ }^{48}{ }^{49}$ possibly because they are under closer medical supervision than non-diabetics. Therefore, a possible explanation for the finding is simply that wild type cases had (by chance) a more localised distribution of stage.

- It is possible that some organochlorine compounds may increase the risk of diabetes. ${ }^{50-54}$ If so, the overrepresentation of diabetics among the seven K-ras wild type cases would tend to mask differences in organochlorine compounds concentrations with the 17 mutated cases. This might partly explain differences with a previous study of ours: we found that mutated cases had significantly higher concentrations of organochlorines than non-mutated cases. ${ }^{33}$

- The 46 subjects with a K-ras mutated tumour were almost three times more likely to be in the upper category of total coffee consumption than the 15 cases without a mutation $(\mathrm{OR}=2.78, \mathrm{p}=0.11)$ (incidentally, the $\mathrm{p}$ value of 1.00 that the authors offer is wrong; the $\mathrm{p}$ value published for caffeinated coffee is also overestimated, while that for decaffeinated coffee is correct). ${ }^{36}$ But polyuria (frequent secretion of urine) and polydipsia (frequent thirst) are common symptoms of diabetes: increased urination is a consequence of osmotic diuresis secondary to sustained hyperglycaemia; this results in a loss of glucose as well as free water and electrolytes in the urine. Thirst is a consequence of the hiperosmolar state. ${ }^{55}$ It is thus plausible that the diabetic patients included in the study had a tendency to drink more liquids than non-diabetics. If so, a spuriously high presence of diabetics in the wild type group may have blurred case-case differences on coffee consumption. A slight bias in the direction we hypothesise would bring their OR closer to the figure of 3.65 that we observed based on 83 mutated and 24 wild type cases, as discussed in this journal. ${ }^{32}{ }^{56}$ Should the study by Slebos et al be thought to provide fresh additional evidence for an association between coffee consumption and K-ras mutations in exocrine pancreatic cancer? One could be inclined to think so, but the first set of questions we posed above makes the judgement uncertain. And so we may be unable to assess another potentially important gene-environment interaction.

\section{MOLECULAR EPIDEMIOLOGY CAN DO BETTER}

More needs to be known about the environmental aetiology of cancer and the causes of genetic alterations in this and other groups of diseases. ${ }^{11-14}{ }^{16}{ }_{19-21}^{24}$ But such knowledge is proving elusive. Perhaps for lack of appropriate studies? (For example, for lack of valid studies that care to assess oncogeneenvironment interactions?). Research funding is at a historical high in the United States, the nation that leads international research on cancer. The study by Slebos et al is only the second attempt to analyse internal concentrations of organochlorine compounds and K-ras mutations in any human cancer. Beyond the merits and limitations of this and other studies, all this reflects the difficulties faced by most of us worldwide, and the limitations of some research approaches to the causes of complex diseases. An open debate on these issues should help to design, conduct, and analyse more valid and meaningful molecular epidemiological studies. It would hence help to add value to research on human genomics-modestly, but distinctly.

\section{ACKNOWLEDGEMENTS}

Thanks are due to J M Corominas, A Salas, L Guarner, J Rifà, S Coll, R Solà, and $\mathrm{M}$ Andreu for scientific advice; to $\mathrm{D} \mathrm{J}$ MacFarlane, $\mathrm{E}$ Fernandez, J L Piñol, S Costafreda, G Castañeda, J Ngo, and A Serrat for technical assistance; to A Amorós for help in drawing the figures; and to P Barbas, L Español, and O Juan for secretarial assistance.

\section{Authors' affiliations}

M Porta, N Malats, M Soler, L Ruiz, D Ayude, F X Real, Institu†

Municipal d'Investigació Mèdica, Universitat Autònoma de Barcelona

and Universitat Pompeu Fabra, Barcelona, Spain

J Vioque, A Carrato, V Barberà, Universidad Miguel Hernández, Alacant, Spain

Funding: partly funded by research grants from Ministerio de Ciencia y Tecnología (CICYT SAF 2000-0097). Fondo de Investigación Sanitaria (95/0017) and Generalitat de Catalunya (BEAi 1998/400011 and DURSI 2001/SGR/406).

Conflicts of interest: none.

Correspondence: Professor M Porta, Institut Municipal d'Investigació Mèdica, Universitat Autònoma de Barcelona, Carrer del Dr Aiguader 80, E-08003 Barcelona, Spain; mporta@imim.es

Accepted for publication 3 April 2002

\section{REFERENCES}

1 Anonymous. Clinton and Blair hail gene 'triumph'. The Guardian 2000;26 Jun.

2 Anonymous. Reading the book of life. White House remarks on decoding of genome. The New York Times 2000;27 Jun.

3 Race T. New economy. There's gold in human DNA, and he who maps it first stands to win on the scientific, software and business fronts. The New York Times 2000; 19 June.

4 Wade N. Long-held beliefs are challenged by new human genome analysis. The New York Times 2001;12 Feb.

5 Butcher J. "Working draft" of human genome completed [news]. Lancet 2001;356:47.

6 Yamey G. Dispute as rival groups publish details of human genome [news]. BM 2001;322:381.

7 Bobrow M, Grimbaldeston AH. Medical genetics, the human genome project and public health. J Epidemiol Community Health 2000:54:645-9.

8 Temple LKF, McLeod RS, Gallinger S, et al. Defining disease in the genomics era. Science 2001;293:807-8.

9 Gould SJ. Humbled by the genome's mysteries. The New York Times 2001;19 Feb.

10 Vineis $\mathbf{P}$, Schulte $P$, McMichael AJ. Misconceptions about the use of genetic tests in populations. Lancet 2001;357:709-12.

11 Rothman N, Wacholder S, Caporaso NE, et al. The use of common genetic polymorphisms to enhance the epidemiologic study of environmental carcinogens. Biochim Biophys Acta 2001;1471:C1-10.

12 Castiel LD. Apocalypse... now? Molecular epidemiology, predictive genetic tests, and social communication of genetic contents. Cad Saúde Pública 1999;15 (suppl 1):73-89.

13 Ishibe N, Kelsey KT. Genetic susceptibility to environmental and occupational cancers. Cancer Causes Control 1997:8:504-13.

14 Vineis $\mathbf{P}$, Malats $N$, Porta $M$, et al. Human cancer, carcinogenic exposures and mutational spectra. Mutat Res 1999;436:185-94.

15 Garner C. Epidemiology. Molecular potential. Nature 1992;360:207-8

16 Foxman B, Riley L. Molecular epidemiology: focus on infection. Am J Epidemiol 2001;153:1135-41.

17 Hunter DJ. The future of molecular epidemiology. Int J Epidemiol 1999;28:S1012-14.

18 Vineis P, McMichael AJ. Bias and confounding in molecular epidemiological studies: special considerations. Carcinogenesis 1998; 19:2063-7.

19 Vineis $\mathbf{P}$, Porta M. Causal thinking, biomarkers and mechanisms of carcinogenesis. J Clin Epidemiol 1996;49:951-6.

20 Vineis $\mathbf{P}$, Malats $N$. Strategic issues in the design and interpretation of studies on metabolic polymorphisms and cancer. In: Vineis P, Malats N, Lang $M$, et al, eds. Metabolic polymorphisms and susceptibility to cancer. IARC Scientific publications, $n^{\circ} 148$. Lyon: International Agency for Research on Cancer, 1999:51-62.

21 Ambrosone CB, Kadlubar FF. Toward an integrated approach to molecular epidemiology. Am J Epidemiol 1997;146:912-18.

22 Dorman JS. Molecular epidemiology: the impact of molecular biology in epidemiology research. Rev Med Chile 2000;128:1261-8.

23 Ellsworth DL, Manolio TA. The emerging importance of genetics in epidemiologic research II. Issues in study design and gene mapping. Ann Epidemiol 1999;9:75-90

24 Mucci LA, Wedren S, Tamimi RM, et al. The role of gene-environment interaction in the etiology of human cancer: examples from cancers of the large bowel, lung and breast. J Intern Med 2001 ;249:477-93.

25 Porta M, Malats N, Real FX, et al. Epidemiología molecular. Med Clin (Barc) 1993;100:475

26 Porta M, Malats N, Corominas JM, et al. Generalizing molecular results arising from incomplete biological samples: expected bias and unexpected findings. Ann Epidemiol 2002:12:7-14.

27 Slattery ML, Edwards SL, Palmer L, et al. Use of archival tissue in epidemiologic studies: collection procedures and assessment of potential sources of bias. Mutat Res Genomics 2000;432:7-14

28 Berger $\mathbf{D H}$, Chang $\mathrm{H}$, Wood $\mathrm{M}$, et al. Mutational activation of K-ras in nonneoplastic exocrine pancreatic lesions in relation to cigarette smoking status. Cancer 1999;85:326-32. 
29 Hruban RH, van Mansfeld ADM, Offerhaus GHA et al. K-ras oncogene activation in adenocarcinoma of the human pancreas. A study of 82 carcinomas using a combination of mutant-enriched polymerase chain reaction analysis and allele-specific oligonucleotide hybridization. Am J Pathol 1993:143:545-54.

30 Malats $\mathbf{N}$, Porta $M$, Corominas JM, et al. Ki-ras mutations in exocrine pancreatic cancer: association with clinico-pathological characteristics, and with tobacco and alcohol consumption. Int J Cancer 1997;70:661-7.

31 Porta M, Malats N, Piñol JL, et al. Response: Relevance of misclassification of disease status in epidemiologic studies of exocrine pancreatic cancer. J Clin Epidemiol 1996;49:602-3.

32 Porta M, Malats N, Guarner L, et al. Association between coffee drinking and K-ras mutations in exocrine pancreatic cancer. J Epidemiol Community Health 1999;53:702-9.

33 Porta M, Malats N, Jariod M, et al. Serum concentrations of organochlorine compounds and K-ras mutations in exocrine pancreatic cancer. Lancet 1999:354:2125-9.

34 Porta M, Jariod M, Malats N, et al. Prevalence of K-ras mutations at diagnosis and serum levels of DDT, DDE, PCBs and other organochlorine compounds in exocrine pancreatic cancer. In: Gress TM, ed. Molecular pathogenesis of pancreatic cancer. Amsterdam: IOS Press, 2000:37-44.

35 Alguacil J, Porta M, Malats N, et al. Occupational exposure to organic solvents and $\mathrm{K}$-ras mutations in exocrine pancreatic cancer. Carcinogenesis 2002;23:101-6.

36 Slebos RJC, Hoppin JA, Tolbert PE, et al. K-ras and p53 in pancreatic cancer: association with medical history, histopathology, and environmental exposures in a population-based study. Cancer Epidemio Biomark Prev 2000;9: 1223-32.

37 Gress TM, ed. Molecular pathogenesis of pancreatic cancer Amsterdam: IOS Press, 2000.

38 Hoppin JA, Tolbert PE, Holly EA, et al. Pancreatic cancer and serum organochlorine levels. Cancer Epidemiol Biomark Prev 2000;9:199-205.

39 Silverman DT, Schiffman M, Devesa S. Diagnostic certainty in pancreatic cancer. J Clin Epidemiol 1996:49:602

40 Cheng L, Wang LE, Spitz MR, et al. Cryopreserving whole blood for functional assays using viable lymphocytes in molecular epidemiologic studies. Cancer Lett 2001;166:155-63.

41 Singer RS, Atwill ER, Carpenter TE, et al. Selection bias in epidemiologic studies of infectious disease using Escherichia coli and avian cellulitis as an example. Epidemiol Infect 2001;126:139-45.
42 Harty LC, Shields PG, Winn DM et al. Self-collection of oral epithelia cell DNA under instruction from epidemiologic interviewers. Am J Epidemiol 2000;151:199-205.

43 Porta M, Costafreda S, Malats N, et al. Validity of the hospital discharge diagnosis in epidemiologic studies of biliopancreatic pathology. Eur J Epidemiol 2000;16:533-41.

44 Porta M. Role of organochlorine compounds in the etiology of pancreatic cancer: a proposal to develop methodological standards. Epidemiology $2001 ; 12: 272-6$.

45 Grunewald K, Lyons J, Frohlich A, et al. High frequency of Ki-ras codon 12 mutations in pancreatic adenocarcinomas. Int $\mathrm{J}$ Cancer 1989:43:1037-41.

46 Motojima K, Urano T, Nagata Y, et al. Mutations in the Kirsten-ras oncogene are common but lack correlation with prognosis and tumor stage in human pancreatic carcinoma. Am J Gastroenterol 1991:86:1784-8

47 Schaeffer BK, Glasner S, Kuhlmann E, et al. Mutated c-K-ras in small pancreatic adenocarcinomas. Pancreas 1994;9:161-5.

48 Girelli CM, Reguzzoni G, Limido E, et al. Pancreatic carcinoma: differences between patients with or without diabetes mellitus. Recent Prog Med 1995:86:143-6.

49 Chari ST, Klee GG, Miller L, et al. Islet amyloid polypeptide is not a satisfactory marker for detecting pancreatic cancer. Gastroenterology $2001 ; 121: 640-5$

50 Morgan DP, Lin LI, Saikaly HH. Morbidity and mortality in workers occupationally exposed to pesticides. Arch Environ Contam Toxicol 1980;9:349-82.

51 Takayama S, Sieber SM, Dalgard DW, et al. Effects of long-term oral administration of DDT on nonhuman primates. J Cancer Res Clin Onco 1989; 125:219-25

52 Henriksen GL, Ketchum NS, Michalek JE, et al. Serum dioxin and diabetes mellitus in veterans of Operation Ranch Hand. Epidemiology 1997:8:252-8

53 Axelson O, Persson B, Wingren G. Dioxin and diabetes mellitus. Epidemiology 1998;9:358-9.

54 Longnecker MP, Michalek JE. Serum dioxin level in relation to diabetes mellitus among Air Force veterans with background levels of exposure. Epidemiology 2000:11:44-8.

55 Greenspan FS, Gardner D, eds. Basic and clinical endocrinology. 6th edn. East Norwalk, CT: Appleton and Lange, 2000.

56 Porta M, Malats N, Alguacil J, et al. Coffee, pancreatic cancer, and K-ras mutations: updating the research agenda. J Epidemiol Community Health 2000;54:656-9.

For just US\$25 you can have instant access to the whole website for 30 days. During this time you will be able to access the full text for all issues (including supplements) available. You will also be able to download and print any relevant pdf files for personal use, and take advantage of all the special features Journal of Epidemiology and Community Health online has to offer.

www.jech.com 